\title{
Cerebral salt-wasting syndrome due to hemorrhagic brain infarction: a case report
}

\author{
Tomotaka Tanaka ${ }^{{ }^{*}}$, Hisakazu Uno ${ }^{2}$, Kotaro Miyashita $^{1}$ and Kazuyuki Nagatsuka ${ }^{1}$
}

\begin{abstract}
Introduction: Cerebral salt-wasting syndrome is a condition featuring hyponatremia and dehydration caused by head injury, operation on the brain, subarachnoid hemorrhage, brain tumor and so on. However, there are a few reports of cerebral salt-wasting syndrome caused by cerebral infarction. We describe a patient with cerebral infarction who developed cerebral salt-wasting syndrome in the course of hemorrhagic transformation.

Case presentation: A 79-year-old Japanese woman with hypertension and arrhythmia was admitted to our hospital for mild consciousness disturbance, conjugate deviation to right, left unilateral spatial neglect and left hemiparesis. Magnetic resonance imaging revealed a broad ischemic change in right middle cerebral arterial territory. She was diagnosed as cardiogenic cerebral embolism because atrial fibrillation was detected on electrocardiogram on admission. She showed hyponatremia accompanied by polyuria complicated at the same time with the development of hemorrhagic transformation on day 14 after admission. Based on her hypovolemic hyponatremia, she was evaluated as not having syndrome of inappropriate secretion of antidiuretic hormone but cerebral salt-wasting syndrome. She fortunately recovered with proper fluid replacement and electrolyte management.

Conclusions: This is a rare case of cerebral infarction and cerebral salt-wasting syndrome in the course of hemorrhagic transformation. It may be difficult to distinguish cerebral salt-wasting syndrome from syndrome of inappropriate antidiuretic hormone, however, an accurate assessment is needed to reveal the diagnosis of cerebral salt-wasting syndrome because the recommended fluid management is opposite in the two conditions.
\end{abstract}

Keywords: Cerebral salt-wasting syndrome, Hemorrhagic brain infarction, Hyponatremia

\section{Introduction}

It is not rare to encounter hyponatremia during the course of acute central nervous system (CNS) diseases. In the literature, hyponatremia complicates about $30 \%$ of subarachnoid hemorrhage cases $[1,2]$ and $16.8 \%$ of head injury cases [3]. Syndrome of inappropriate secretion of antidiuretic hormone (SIADH) and cerebral salt-wasting syndrome (CSWS) have been reported as the major causes of hyponatremia, while the therapeutic policy is essentially opposite because of a difference in the circulatory blood volume. Therefore, it is crucial to differentiate SIADH and CSWS from the clinical viewpoint. There have been many reports of CSWS following subarachnoid hemorrhage, but CSWS accompanying ischemic cerebrovascular diseases

\footnotetext{
* Correspondence: tanakat@hsp.ncvc.go.jp

'Division of Neurology, Department of Stroke and Cerebrovascular Diseases, National Cerebral and Cardiovascular Center, 5-7-1 Fujishiro-dai, Suita, Osaka 565-8565, Japan

Full list of author information is available at the end of the article
}

has been rarely reported. We report the case of a woman with cerebral infarction who developed CSWS in the course of hemorrhagic transformation.

\section{Case presentation}

A 79-year-old Japanese woman with a past medical history of hypertension and arrhythmia suddenly developed left hemiparesis and drowsy state, and was sent to our emergency room. A neurological examination showed mild consciousness disturbance, conjugate deviation to right, mild dysarthria, left unilateral spatial neglect, left facial and motor weakness, and left sensory disturbance. Magnetic resonance imaging depicted a large high intensity lesion in right middle and posterior cerebral arterial territory on diffusion weighted images, and her right internal carotid artery was obstructed on magnetic resonance arteriography (MRA). Atrial fibrillation was observed on electrocardiogram. No other vascular lesion which may have caused the disease was noted, suggesting cardiogenic 


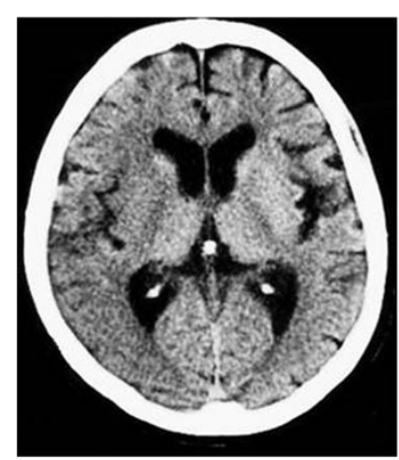

Day 1

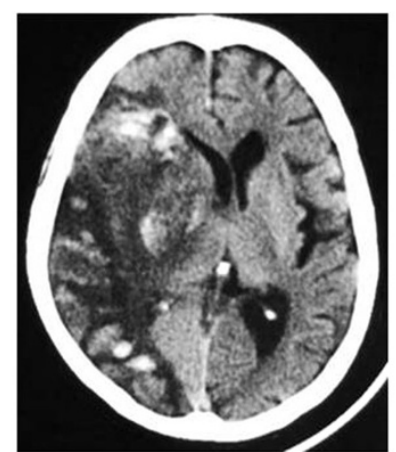

Day 15

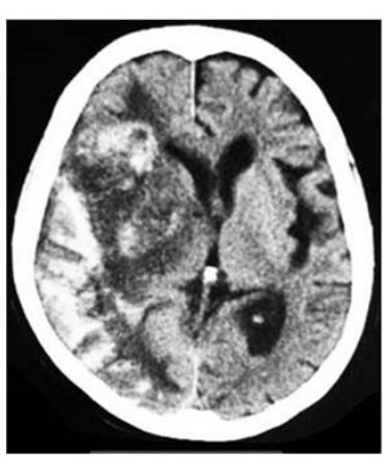

Day 24

Figure 1 Changes of cerebral infarction in computed tomography. Slight, broad low density area in the right middle cerebral artery territory was depicted on day 1 , showing the early cerebral infarction. Large low density area with midline shift and high density was depicted on day 15 and day 24, showing hemorrhagic transformation and severe brain edema.

cerebral embolism. Her blood analysis showed almost normal findings including hemoglobin $13.0 \mathrm{~g} / \mathrm{dL}$, hematocrit $39.8 \%$, sodium $(\mathrm{Na}) 142 \mathrm{mEq} / \mathrm{L}$, blood urea nitrogen (BUN) $16 \mathrm{mg} / \mathrm{dL}$, and creatinine, $0.69 \mathrm{mg} / \mathrm{dL}$. In addition to anti-edema therapy, the continuous intravenous infusion of heparin was initiated on the following day because no apparent hemorrhage was identified on computed tomography (CT). No marked change was noted in neurological signs, and her brain edema tended to improve on CT. On day 14, her right internal carotid artery became patent on MRA, and hemorrhage occurred in the infarct region of her right middle cerebral artery. Thus, heparin administration was discontinued on the same day.

However, hemorrhage and brain edema expanded on day 15 (Figure 1), and consciousness disturbance deteriorated. Concurrently, in addition to polyuria and hyponatremia (Figure 2 and Table 1), features of dehydration appeared, such as reduction of skin turgor, collapse of

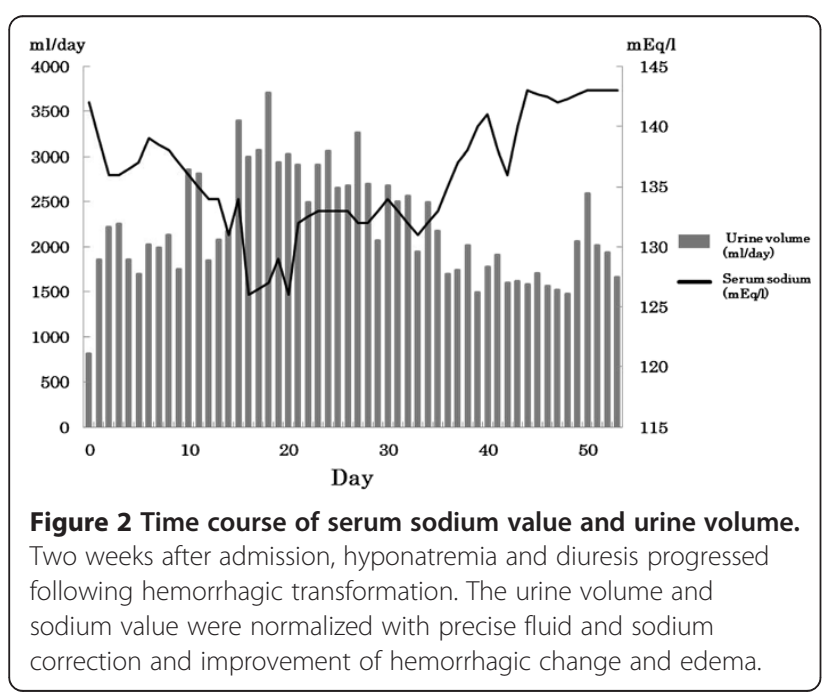

the inferior vena cava (IVC), and weight loss. Fluid replacement induced only an increase of urine volume and failed to correct dehydration tendency (input of $3410 \mathrm{~mL}$ compared to a total urinary output of $3710 \mathrm{~mL}$ on day 20). Considering the possibility of diabetes insipidus, a water deprivation antidiuretic hormone stimulation test (by inserting $10 \mathrm{mcg}$ of desmopressin into a nostril by using the spray once) was performed on day 28 , however, her urine volume did not decrease. Despite adequate fluid replacement, she was in negative fluid balance and her weight had decreased by $4.6 \%$, from $39.2 \mathrm{~kg}$ to $37.4 \mathrm{~kg}$. An endocrinological examination excluded SIADH because of hydration features. CSWS was assumed to be a more probable pathological state, and salt supply was added to fluid replacement on day 29. Following the alleviation of hemorrhagic transformation, her excessive urine volume slowly decreased, and her hyponatremia and dehydration improved. She was transferred to another rehabilitation hospital about 2 months after admission.

\section{Discussion}

CSWS was reported as a condition of urine volume increase and excess loss of urinary $\mathrm{Na}$ accompanied by

Table 1 The transition of biochemical parameters related to the abnormality of sodium metabolism in the patient

\begin{tabular}{llll}
\hline & \multicolumn{3}{l}{ Days from onset } \\
\hline Biochemical data & Day 15 & Day 25 & Day 52 \\
Serum sodium (mEq/L) & 134 & 133 & 143 \\
Uosm (Osm/kg.H2O) & 454 & 385 & 266 \\
Posm (Osm $/ \mathrm{kg} \cdot \mathrm{H} 2 \mathrm{O})$ & 279 & no data & no data \\
Urinary sodium excretion (mEq/day) & 219 & 239 & 179 \\
FEUA (\%) & 26 & 16 & 12 \\
\hline
\end{tabular}

FEUA, fractional excretion of uric acid; Posm, plasma osmolality; Uosm, urine osmolality. 
Table 2 Patients with cerebral salt-wasting syndrome accompanying cerebral infarction

\begin{tabular}{|c|c|c|c|c|c|c|c|c|c|c|c|c|}
\hline Sex/age & $\begin{array}{l}\text { Cerebral } \\
\text { infarction type }\end{array}$ & Lesion & $\begin{array}{l}\text { Excessive } \\
\text { edema }\end{array}$ & $\begin{array}{l}\text { Hemorrhagic } \\
\text { transformation }\end{array}$ & Comorbidity & $\begin{array}{l}\text { Days from } \\
\text { onset (days) }\end{array}$ & Treatment & $\begin{array}{l}\text { Serum sodium } \\
\text { concentration } \\
\text { (mmol/L) }\end{array}$ & Urine volume & $\begin{array}{l}\text { Uosm } \\
\text { (mL/day) }\end{array}$ & $\begin{array}{l}\text { Posm } \\
\text { (mL/day) }\end{array}$ & Ref. no. \\
\hline$M / 3$ & $\begin{array}{l}\text { Dissection } \\
\text { of ICA }\end{array}$ & $\begin{array}{l}\text { Right MCA } \\
\text { (broad) }\end{array}$ & Yes & No & Head injury & 6 & $\begin{array}{l}\text { Intravenous } \\
\text { saline }\end{array}$ & 122 & $\begin{array}{l}4.3 \mathrm{~mL} / \mathrm{kg} / \mathrm{hour} \\
\text { (BW: } 17.0-17.5 \mathrm{~kg} \text { ) }\end{array}$ & 607 & 219 & [11] \\
\hline \multirow[t]{3}{*}{$F / 38$} & Unknown & $\begin{array}{l}\text { Right MCA } \\
\text { (broad) }\end{array}$ & Yes & no data & $\begin{array}{l}\text { Systemic lupus } \\
\text { erythematosus }\end{array}$ & 5 & $\begin{array}{l}\text { Intravenous } \\
\text { saline }\end{array}$ & 112 & $\begin{array}{l}\text { 2800mL/day (BW: } \\
\text { no data) }\end{array}$ & 280 & 276 & [13] \\
\hline & & & & & Lupus nephritis & & Hydrocortisone & & & & & \\
\hline & & & & & $\begin{array}{l}\text { Tuberculous } \\
\text { meningoencephalitis }\end{array}$ & & & & & & & \\
\hline \multirow[t]{2}{*}{$F / 79$} & $\begin{array}{l}\text { Cardiac } \\
\text { embolism }\end{array}$ & Right & Yes & Yes & Atrial fibrillation & 15 & $\begin{array}{l}\text { Intravenous } \\
\text { saline }\end{array}$ & 134 & $\begin{array}{l}3710 \mathrm{~mL} / \text { day (BW: } \\
37.4-39.2 \mathrm{~kg})\end{array}$ & 454 & 279 & $\begin{array}{l}\text { Current } \\
\text { report }\end{array}$ \\
\hline & & $\begin{array}{l}\text { MCA } \\
\text { (broad) }\end{array}$ & & & Hypertension & & Oral salt & & & & & \\
\hline
\end{tabular}

BW, body weight; F, female; ICA, internal carotid artery; M, male; MCA, middle cerebral artery; Posm, plasma osmolality; Uosm, urine osmolality. 
weight loss in intracranial hemorrhagic disorders [4]. Hyponatremia is a common complication in CNS diseases, especially head injury and cerebrovascular disorder, and has been regarded as SIADH in general. Considering dehydration associated with hyponatremia, however, CSWS was more common than SIADH in CNS diseases as Nelson et al. pointed out [5]. Since then, many cases of CSWS have been reported, while the pathogenesis of CSWS has remained unexplained. Some reports showed that atrial and brain natriuretic peptides (ANP and BNP) from damaged $\mathrm{CNS}$ tissues and abnormality of the sympathetic nervous system might induce CSWS [6-9]. That is, the increasing natriuretic peptide secretion and catecholamine might cause natriuresis via reduced renin secretion [9-12]. In our case, the level of ANP and BNP continued to be elevated (BNP 250.2pg/mL, ANP 200pg/mL) after the improvement of cardiac function.

CSWS is frequently associated with CNS hemorrhagic diseases, but only a few cases of CSWS in brain infarction have been reported [11-13]. The previous case reports of cerebral infarction had the characteristics of severe physical stress including systemic autoimmune disease, serious infection, and trauma (Table 2) $[11,13]$. These systemic complications might be more susceptible to developing CSWS than localized involvement in patients with cerebral infarction. In fact, in our patient, manifestation of CSWS appeared not in the early stage but in the advanced stage with hemorrhagic transformation and excessive edema of cardiogenic brain infarction.

Whereas SIADH management requires strict fluid volume restriction, the treatment policy of CSWS is adequate fluid balance control and substitution of sodium chloride. Distinguishing these conditions may be unexpectedly difficult [14] because they show much in common; they have overlapping clinical and biochemical signs such as absence of peripheral edema, normal renal and adrenal function, low serum $\mathrm{Na}$, low serum osmolality, and high urinary Na. Glycerol and mannitol as hyperosmolar agents are commonly used for brain edema, making it difficult to assess the true urinary and plasma volume. Extracellular volume assessment is a key factor to distinguish CSWS from SIADH. Due to a lack of precise assessment of the amount of extracellular fluid, it is necessary to note clinical dehydration signs such as reduction of turgor, raised heartbeat, body weight loss and collapsed IVC as well as laboratory findings including BUN/creatinine ratio. Furthermore, the persistence of hypouricemia and elevation of fractional excretion of uric acid (FEUA) even after the correction of hyponatremia may contribute to differentiate CSWS from SIADH as already reported [15]. In our patient, the serum $\mathrm{Na}$ level normalized on day 52, but the FEUA was still 10\% higher than normal range (Table 1).

\section{Conclusions}

We reported a case of CSWS following cerebral infarction. In patients with severe stroke, disturbances of $\mathrm{Na}$ metabolism are frequent. It is important to investigate the causes of hyponatremia in patients with stroke, considering the differential diagnosis of SIADH and CSWS by assessing the dehydration signs.

\section{Consent}

Written informed consent was obtained from the patient for publication of this case report and accompanying images. A copy of the written consent is available for review by the Editor-in-Chief of this journal.

\section{Abbreviations}

ANP: Atrial natriuretic peptides; BNP: Brain natriuretic peptides; BUN: Blood urea nitrogen; CNS: Central nervous system; CSWS: Cerebral salt-wasting syndrome; CT: Computed tomography; FEUA: Fractional excretion of uric acid; IVC: Inferior vena cava; MRA: Magnetic resonance arteriography; Na: Sodium; SIADH: Syndrome of inappropriate secretion of antidiuretic hormone..

\section{Competing interests}

The authors declare that they have no competing interests.

\section{Authors' contributions}

$\Pi T$ wrote the manuscript. $\Pi T$ and $\mathrm{HU}$ acquired patient data. $\mathrm{HU}$ and $\mathrm{KM}$ reviewed the case notes and were major contributors in writing the manuscript KN edited the manuscript and provided suggestions. All authors read and approved the final manuscript.

\section{Acknowledgements}

No funding was obtained for this report.

\section{Author details}

${ }^{1}$ Division of Neurology, Department of Stroke and Cerebrovascular Diseases, National Cerebral and Cardiovascular Center, 5-7-1 Fujishiro-dai, Suita, Osaka 565-8565, Japan. ${ }^{2}$ Department of Internal Medicine, Takarazuka Sanda Hospital, 2-22-10 Nishiyama, Sanda, Hyogo 669-1537, Japan.

Received: 3 April 2014 Accepted: 16 May 2014

Published: 23 July 2014

\section{References}

1. Kurokawa Y, Uede T, Ishiguro M, Honda O, Honmou O, Kato T, Wanibuchi M: Pathogenesis of hyponatremia following subarachnoid hemorrhage due to ruptured cerebral aneurysm. Surg Neurol 1996, 46:500-507. discussion 507-508.

2. Hasan D, Wijdicks EF, Vermeulen M: Hyponatremia is associated with cerebral ischemia in patients with aneurysmal subarachnoid hemorrhage. Ann Neurol 1990, 27:106-108.

3. Moro N, Katayama Y, Igarashi T, Mori T, Kawamata T, Kojima J: Hyponatremia in patients with traumatic brain injury: incidence, mechanism, and response to sodium supplementation or retention therapy with hydrocortisone. Surg Neurol 2007, 68:387-393.

4. Peters JP, Welt LG, Sims EA, Orloff J, Needham J: A salt-wasting syndrome associated with cerebral disease. Trans Assoc Am Physicians 1950, 63:57-64.

5. Nelson PB, Seif SM, Maroon JC, Robinson AG: Hyponatremia in intracranial disease: perhaps not the syndrome of inappropriate secretion of antidiuretic hormone (SIADH). J Neurosurg 1981, 55:938-941.

6. Palmer BF: Hyponatremia in patients with central nervous system disease: SIADH versus CSW. Trends Endocrinol Metab 2003, 14:182-187.

7. Harrigan MR: Cerebral salt wasting syndrome. Crit Care Clin 2001, 17:125-138.

8. Rabinstein AA, Wijdicks EF: Hyponatremia in critically ill neurological patients. Neurologist 2003, 9:290-300. 
9. Berendes E, Walter M, Cullen P, Prien T, Van Aken H, Horsthemke J, Schulte M, von Wild $K$, Scherer R: Secretion of brain natriuretic peptide in patients with aneurysmal subarachnoid haemorrhage. Lancet 1997, 349:245-249.

10. Harrigan MR: Cerebral salt wasting syndrome: a review. Neurosurgery 1996, 38:152-160.

11. Berger TM, Kistler W, Berendes E, Raufhake C, Walter M: Hyponatremia in a pediatric stroke patient: syndrome of inappropriate antidiuretic hormone secretion or cerebral salt wasting? Crit Care Med 2002, 30:792-795.

12. Singh S, Bohn D, Carlotti AP, Cusimano M, Rutka JT, Halperin ML: Cerebral salt wasting: truths, fallacies, theories, and challenges. Crit Care Med 2002, 30:2575-2579

13. Loo KL, Ramachandran R, Abdullah BJ, Chow SK, Goh EM, Yeap SS: Cerebral infarction and cerebral salt wasting syndrome in a patient with tuberculous meningoencephalitis. Southeast Asian $J$ Trop Med Public Health 2003, 34:636-640.

14. Oh MS, Carroll HJ: Cerebral salt-wasting syndrome. We need better proof of its existence. Nephron 1999, 82:110-114.

15. Maesaka JK, Fishbane S: Regulation of renal urate excretion: a critical review. Am J Kidney Dis 1998, 32:917-933.

doi:10.1186/1752-1947-8-259

Cite this article as: Tanaka et al.: Cerebral salt-wasting syndrome due to hemorrhagic brain infarction: a case report. Journal of Medical Case Reports 2014 8:259.

\section{Submit your next manuscript to BioMed Central and take full advantage of:}

- Convenient online submission

- Thorough peer review

- No space constraints or color figure charges

- Immediate publication on acceptance

- Inclusion in PubMed, CAS, Scopus and Google Scholar

- Research which is freely available for redistribution 